\title{
The 2022 FIFA World Cup, the exploitation of migrant workers, and the role of transnational governing networks
}

Edition 8, 2021

Dr Laura Foley and Professor Nicola Piper

DOI: 10.37839/MAR2652-550X8.14

Over the past decade, the eyes of the world have been increasingly drawn to the exploitative working and living conditions faced by the two million migrant workers in Qatar. This is due to Qatar hosting the 2022 FIFA World Cup, a mega-sporting tournament that could offer the potential to catalyse progress on human and labour rights as the event is of 'high profile nature and global reach'.

The working and living conditions of the mostly South Asian migrant workers who are hired on temporary, employer-tied contracts to construct the infrastructure for the World Cup have been widely exposed as below dignified standards, so much so that some refer to this situation as 'modern day slavery'.

Our analysis examines the push to challenge the human rights violations experienced by migrant workers in Qatar and the efforts to influence Qatar's policy reform. We argue that, at the heart of this process, are transnational multi-actor governing networks.

Our concept of 'transnational governing networks' (TGNs) allows for a multi-level, multi-actor analysis of what brought about the recent labour reforms in Qatar that are to benefit precarious migrant workers, including those involved in the South 
Asia-Qatar migration corridor. Our key argument is that while the space and avenues for collective political organising are severely constrained in Qatar, vibrant transnational network activity among a diverse range of actors at the intersection of national, regional, and global policymaking levels has built up ever since Qatar was declared host of the 2022 World Cup.

\section{Hiring and employment practices in Qatar}

Qatar has been a key destination country for migrant workers since the 1960s. Migrants constitute over 95 percent of the total workforce in the country and more than 80 percent of the population. This mirrors the situation in most Gulf Cooperation Council states where labour migration from Asia has been subject to increased academic attention (see e.g. Piyasiri Wickramasekera, Andrew Gardner, Binod Khadria, Ray Jureidini, Bilesha Weeraratne, and S. Irudaya Rajan and Gina Zacharia Oomen).

After Qatar was awarded the 2022 World Cup in December 2010, its population increased at an astounding rate between 2012 and 2013 (+10.5 percent) with around 'twenty new people... added to the population every hour'. Many of Qatar's newly hired workers hail from countries in South Asia where insufficient earning opportunities force them to seek work overseas. However, to access overseas employment through a legal pathway, South Asian migrants are restricted to schemes that only offer temporary contracts for a select range of labour market sectors where they occupy mostly jobs classified as low-skilled (which translates into low-wage). Those include construction, hospitality, services, and domestic work.

The immigration and employment laws which govern temporary contract migration to Qatar grant significant power to employers and give rise to highly abusive hiring, living, and working conditions which start with the involvement of an exploitative recruitment system rife with migration intermediaries, many of whom charge excessive fees which leave migrants heavily indebted. Research conducted by 
Impactt (an ethical trade consultancy) found that migrant workers who are building Qatar's World Cup stadiums paid on average \$1,500 USD in recruitment fees, with workers from Bangladesh paying as much as $\$ 2,900$ USD. This is the equivalent of 7-14 months' wages, as the monthly minimum wage was $\$ 206$ USD at the time of the research.

The infamous sponsorship system practiced across the Gulf, Kafala, further exacerbates worker exploitation. This system ties workers to individual employers who, as sponsors of work permits, are in full control of migrants who cannot change jobs mid-contract or return to their country of origin without their employers' permission. For low-wage temporary migrant workers, there are no pathways to permanency or avenues for family reunification, resulting in workers not only separated from their families and communities at home, but also segregated from society in Qatar due to the location of their workplaces and accommodation arrangements. Given the absence of labour unions and other dispute settlement mechanisms, there have been limited channels for recourse in the event of contract violations and other abuses. In light of this situation, the creation of organisational networks operating across place and space in order to assert influence on the situation in Qatar are important.

\section{Transnational Governing Networks}

Our discussion of transnationalism departs from the individualised, micro-level approach taken in the early work by anthropologists who introduced this concept into migration studies in the 1990s. Building on the work by Steven Vertovec who highlighted the interdependence of institutional processes of cross-border movements and Thomas Faist's observation in relation to the missing meso-level in studies of transnationalism, we understand transnationalism from an organisational network perspective in relation to the various sites and levels of policymaking and implementation involving actors who operate across borders. 
Our analysis seeks to contribute to the wealth of literature on transnational labour governance that has often focused on the challenges of regulating labour across borders. Scholars have highlighted the problems with auditing and trying to hold corporations to account for violations in their supply chains (e.g. Ingrid Landau and Tess Hardy), and the difficulties of transnational corporate safety initiatives (e.g. Zobaida Khan), with textile manufacturing having receiving particular attention (see e.g. Felix Beyers and Harald Heinrichs).

Migration studies experienced its 'transnational' turn during the 1990s which coincided with the re-emergence of interest in the link between international migration and development which centred on the idea that, through the sending of remittances and acquisition of skills, labour migration could boost (mostly economic) development and help to alleviate poverty in workers' home countries. In the early 2000s, the United Nations primarily framed international migration as an issue of international development which led to the 'migration-development' nexus gaining prominence in the global policymaking agenda, with migrants at the centre as 'agents of development' (see Matt Withers and Nicola Piper). Yet, as research on migrant workers' human and labour rights has demonstrated, the average migrant's ability to function as an agent of development is severely circumscribed by the precarious conditions that they face as low-wage, temporary workers.

Migrants' labour agency is strictly curtailed in Qatar. This is not only due to Qatar's restrictive migration and employment regime, but also stems from the limited space, if any, for collective mobilisation and political activism as labour unions (in the traditional sense) are absent from labour market institutions. Migrant workers' ability to advocate for their own rights is diminished further as the right to form unions (generally) is restricted and migrants are legally prohibited from joining the only permitted trade union. Non-governmental organisations within Qatar also face restrictions as they need permission from the Qatari government in order to operate, and the state has a history of harassing independent activists and arresting migrant activists. This is the classic scenario that has inspired Margaret Keck and Kathryn Sikkink's thinking around transnational advocacy networks and the so-called 
'boomerang' pattern of influence which refers to political pressure for reform being exerted from the 'outside in'.

Given the extremely limited space for political advocacy and organising at the mesolevel within Qatar, migrant workers and their allies have had to rely on external pressure to affect domestic change. Via the 'boomerang' approach, those within Qatar have sought assistance from those outside Qatar. The subsequent transnational networks that have developed to contest Qatar's migration governance system includes a broad array of members operating at various policy levels and sites. These include civil society organisations (CSOs), global unions, and international non-governmental organisations (INGOs) alongside regional and international organisations beyond those who are part of the United Nations.

Drawing on regulation and governance scholarship (e.g. Peter Drahos), we argue that the multi-level, multi-actor alliances that have formed in response to the plight of migrant workers in Qatar should be reconceptualised as 'transnational governing networks' (TGNs). These networks are largely centred around strategies for coordinated action on specific policy changes and are led by global actors like Building and Wood Workers International (the global union federation in charge of the construction sector) and the International Labour Organisation (ILO), alongside an array of CSOs.

Numerous studies have shown how utilising a 'network approach' is a key way to investigate how actors interact and coordinate to develop public and social policy goals (Silke Adam and Hanspeter Kriesi) such as labour standards. Our concept of TGNs builds on the theoretical underpinnings of 'transnational advocacy networks' (Keck and Sikkink); 'transnational labour rights' activism' (see e.g. Sabrina Zajak and Marissa Brookes), and; the cross-border and cross-organisational 'networks of labour activism' (see Zajak et al.).

TGNs share many similarities with transnational advocacy networks (TANs) because the actors involved are external 'advocates [who] plead the causes of others', who 
share a common rights-based discourse (in our example, 'decent work' for migrants), and who are advocating for policy change in a state which is violating the rights of people within their territory. Other commonalities that TGNs have with TANs include the types of members and some of the advocacy-related tactics that they deploy (especially, as we will show, the campaigns that INGOs and labour unions have launched). Additionally, some of the tactics used by TGNs may appear similar to those deployed by transnational labour alliances (TLAs).

However, we argue that TGNs actually differ from advocacy networks and labour alliances, and that they have their own distinct qualities that require the development of a new classification. Firstly, the membership of TGNs is broader than the workers and labour activists who make up TLAs. The second key difference concerns the targets of TGNs' actions: while TANs mainly target states and TLAs mainly target employers, TGNs target states, employers, and corporations, in our case, the Qatari government, FIFA, its sponsors, and the construction companies building the World Cup stadiums, alongside the raft of labour intermediaries. The realisation that policy reform requires a multi-directional approach is also what Regulation Theory and governance studies have highlighted. This leads to the third distinguishing feature of TGNs which is that they are centred on engaging in direct coordinated action to affect policy change.

TGNs are, thus, a hybrid of the types of transnational networks that have come before yet they are uniquely defined by a combination of who their members are, what (individual and collective) strategies they deploy, and where the interactions take place. TGNs offer 'small' players, such as local NGOs in Qatar, the opportunity to network with 'big' influential players like global trade unions that have the convening power required to engage directly with other big players: governments and global organisations like FIFA. The United Nations, in our case through the ILO, provides a platform where network members can interact, and new members can be enrolled, while also serving as a mechanism where the grievances of migrant workers can be raised, and where action can be taken (see Ian Hurd). 


\section{The strategies of TGNs to push for labour reforms}

Since 2010, a vibrant range of transnational network activity has emerged to challenge Qatar's exploitative labour migration governance system. Organisational actors within the network have deployed various multifaceted approaches to draw international attention to the plight of migrant workers in Qatar. Actors have deployed a raft of advocacy-focused strategies that have centred on campaigns to raise public awareness (such as those by Amnesty International and Human Rights Watch), and campaigns asking corporations associated with the 2022 World Cup to speak out against migrant worker abuses in their supply chains. Building and Wood Workers International (BWI) led the targeted action against FIFA by starting a 'Red Card for FIFA' campaign; and the International Trade Union Confederation (ITUC), the Trades Union Congress (TUC), Skins sportswear, and the New FIFA Now group launched a similar campaign targeting FIFA's sponsors.

However, the main strategy that characterises TGNs, and that differentiates them from TANs, has been their push for policy change through: i) their engagement with established global complaints' mechanisms, and ii) the creation of new avenues for lodging formal complaints. This involved first the use of the ILO's internal complaint system: in 2013, the ITUC and BWI brought a 'representation' against Qatar to the ILO that alleged 'non-observance' of the ILO's Forced Labour Convention 1930. In 2014, workers' representatives from the ILO brought a complaint against Qatar that alleged 'egregious non-observance' of the ILO's Forced Labour Convention 1930 and the Labour Inspection Convention 1947. The complaint alleged that Qatar had taken no effective measures to amend its recruitment and employment system for migrant workers despite repeated warnings that this system perpetuated highly exploitative conditions that facilitate the 'exaction of forced labour' by employers.

BWI then created further avenues for lodging formal complaints. In 2015, it filed a case against FIFA under the OECD Guidelines for Multinational Enterprises which 
alleged that FIFA failed to engage in due diligence in relation to documented instances of human rights' violations against migrant construction workers in Qatar before awarding the tournament to Qatar. This complaint culminated in FIFA 'accept[ing] its responsibility to use its leverage in Qatar to ensure decent and safe working conditions' for migrant workers constructing the World Cup infrastructure.

We argue that the official complaints lodged by BWI, ITUC-BWI, and worker delegates of the ILO, is a strategy which signifies a distinct shift from advocacy, to 'action' as it goes beyond the awareness-raising, and 'naming and shaming' tactics of TANs, and involves influential organisations with convening power. These complaints, alongside increasing international pressure stemming from international media coverage and international campaigns, set off a chain of important events that saw the Qatari government increasingly engage with the ILO, the ITUC, and BWI. These events include a number of high-level visits by ILO representatives to Qatar, the launch of a three-year (2018-2020) ILO Technical Cooperation programme in Qatar, and the establishment of an ILO Project Office in Qatar in 2018.

Furthermore, Qatar's Supreme Committee for Delivery and Legacy (tasked with overseeing the preparations for the 2022 World Cup) signed an agreement with BWI in 2016 to conduct joint inspections at construction and accommodation sites. Furthermore, another agreement was signed in 2017 between BWI and Qatari and French construction companies that permitted BWI to conduct joint inspections of construction sites and workers' dormitories. The aforementioned key actions by BWI, ITUC-BWI, and worker delegates of the ILO, along with the range of campaigns to apply pressure on FIFA and the Qatari government, culminated in the Qatari government committing to 'align its laws and practices with international labour standards'. In this sense, the TGNs managed to turn advocacy into action.

\section{Qatar's 'historic' labour reforms and their}




\section{limitations}

Following more than a decade of transnational efforts by workers' organisations, CSOs, and INGOs, assisted by the ILO, the government of Qatar enacted a range of significant labour reforms between 2020 and 2021, which include the commitment to dismantle the infamous Kafala sponsorship system. The specific changes include establishing a non-discriminatory minimum wage for temporarily contracted migrants, removing the requirement of a No-Objection Certificate in order to change jobs, and removing the requirement of an exit permit to leave the country. Other changes include amending the permissible outside working hours during the summer months, and increasing the number of Labour Dispute Resolution Committees which had been established in 2018 to address workers' complaints. This builds on some of the work undertaken by Qatar's Supreme Committee to improve the working conditions for stadium-related projects by declaring the charging of recruitment fees unlawful and by instituting Workers' Welfare Forums (Workers' Committees).

The ILO has heralded these labour reforms as a key landmark that 'will greatly support the rights of migrant workers' with the ITUC observing that these changes mark a 'new era for workers' rights' in Qatar. However, this raises the question as to whether such changes significantly move the goalposts for migrants' rights in Qatar or just shift them slightly. Some observers fear that Qatar's reforms do not amount to much more than a PR stunt. On paper, the content of the reforms offer the promise of improving some aspects of the labour migration experience, with the removal of the No-Objection Certificate, the new minimum wage, and new working hours in particular having the potential to substantially benefit migrant workers. It is also positive that these labour reforms are to be applied to all workers so therefore should cover domestic workers.

However, as noted by Human Rights Watch, there are still parts of Qatar's governance system that continue to expose migrants to forced labour conditions as 
some 'legal provisions that facilitate abuse and exploitation of migrant workers remain' unchanged. Furthermore, the institutional infrastructure in Qatar remains weak: there are still inadequate labour inspection mechanisms and insufficient enforcement measures. The lack of enforcement and penalties also raises concerns as to whether employers will abide by the new rules. In particular, the ability of workers to change jobs, which is now legally permissible, is proving to be more difficult in practice. Migrant workers have highlighted that some employers have rejected workers' applications to change employers, with some workers facing threats from their sponsor for requesting a job change, while others were ultimately deported for attempting to change jobs (see e.g. reports by Al Jazeera and BWI). Furthermore, while the establishment of Workers Committees at some worksites is a positive step, the right to form unions and to strike remains restricted. Strike action by migrant workers still entails an increased risk of deportation.

The work by TGNs is, therefore, far from done. Labour reform, like any other social change, is a lengthy, non-linear process that unfolds over time. Concerted and sustained engagement with Qatar and FIFA by multiple actors operating from multiple sites and levels is part of what distinguishes TGNs from advocacy networks.

The TGNs that have emerged in response to Qatar's hostile migration and labour governance system constitute a vital component in the functioning of the international labour rights' regime. The coordinated actions taken by organisations within these networks to address the rights' violations that migrant workers face have had a demonstrable impact as Qatar has enacted historic reforms to amend how labour migration is governed. While ongoing challenges remain to the full realisation of all migrant workers' human rights and labour rights in Qatar, one clear conclusion can be drawn: the CSOs and unions who lead this network, in conjunction with the ILO, deserve the golden boot for their transnational governing efforts.

Authors: Dr Laura Foley and Professor Nicola Piper

Image: Migrant workers fasten metal rods together at a construction site. Credit: 


\section{MELBOURNE ASIA REVIEW}

November 10, 2021

ILO/Flickr. 